\title{
IDENTIFIKASI JENIS BATUAN MENGGUNAKAN METODA GEOLISTRIK TAHANAN JENIS KONFIGURASI WENNER DI UNIVERSITAS NEGERI PADANG KAMPUS AIR TAWAR
}

\author{
Elvi Novia $\mathbf{S}^{*}$, Akmam $^{* *)}$, dan Fatni Mufit $\left.{ }^{* *}\right)$ \\ *) Mahasiswa Jurusan Fisika FMIPA UNP, email : elvi.novia.s@gmail.com \\ **) Dosen Jurusan Fisika FMIPA UNP, email : akmamdatuk@ gmail.com, \\ fatni.mufit@gmail.com
}

\begin{abstract}
The research about kinds of rocks has been done in Padang State University Air Tawar campus. Kinds of rocks can be determined by knowing the resistivity value. Wenner resistivity geoelectrical method was used to determine the rocks resistivity value. The research was done to determine the rocks resistivity value and kinds of rocks in Padang State University, Air Tawar campus. Automatic measurement was done using ARES (Automatic Resistivity) and interpretation of data was done using Res2dinv software and Least Square inversion. The result of data interpretation shows range of rocks resistivity value at sounding point $00^{\circ} 53^{\prime} 44,0^{\prime \prime} S$ and $100^{\circ} 20^{\prime} 79,8^{\prime \prime} E$ in $1^{\text {st }}$ line is 0,675-300,1 m, at sounding point $00^{\circ} 53^{\prime} 53,1^{\prime \prime} S$ and $100^{\circ} 21^{\prime} 02,8^{\prime \prime} E$ in $2^{\text {nd }}$ line is $0,0145-208 \mathrm{~m}$, at sounding point $00^{\circ} 53^{\prime} 48,9^{\prime \prime} S$ dan $100^{\circ} 20^{\prime} 50,6^{\prime \prime} E$ in $3^{\text {rd }}$ line is $0,118-243,7 \mathrm{~m}$, and at sounding point $00^{\circ} 53^{\prime} 55,7$ " $S$ and $100^{\circ} 21^{\prime} 02,3^{\prime \prime} E$ in $4^{\text {th }}$ line is 0,195-1842 m. Kinds of rocks that are found in the research are Clays, Sandstones, Alluvium, Sands and also Groundwater.
\end{abstract}

Keywords: Resistivity geoelectrical, Wenner configuration, Rock

\section{PENDAHULUAN}

Universitas Negeri Padang (UNP) Kampus Air Tawar merupakan salah satu Perguruan Tinggi Negeri yang berada di daerah Padang yang berperan aktif dalam perkembangan ilmu pengetahuan di Indonesia. Upaya untuk mendukung peran tersebut dipengaruhi oleh dua faktor, berupa faktor non fisik dan faktor fisik. Faktor non fisik diantaranya kualitas mahasiswa, dosen dan sebagainya, sedangkan faktor fisik salah satunya bisa dilihat dari kualitas bangunan yang ada di lingkungan UNP. Informasi jenis batuan bawah permukaan bumi bisa menjadi salah satu bahan pertimbangan, bagi pihak yang akan merancang kontruksi bangunan agar memperoleh kualitas yang baik.
Batuan merupakan material yang mengandung satu atau beberapa mineral dan berbentuk padatan. Awalnya batuan berasal dari magma yang meleleh ke arah permukaan bumi. Suhu permukaan bumi yang lebih rendah dari suhu di dalam bumi mengakibatkan terjadilah pembekuan magma yang membentuk batuan. Berdasarkan kejadian atau cara terbentuknya batuan dibedakan menjadi tiga kelompok utama, yaitu batuan beku, batuan sedimen, dan batuan metamorf.

Kota Padang secara geologi dibentuk oleh endapan permukaan, batuan vulkanik dan intrusi serta batuan sedimen dan metamorf. Berdasarkan peta geologi disimpulkan bahwa batuan di Kota Padang didominasi oleh aluvium dan batuan gunung api sebagaimana yang diungkapkan 
oleh Danida (2009: 13) "Kota Padang terdiri dari aluvium 31,03\% dan batuan gunung api 50,32\%".

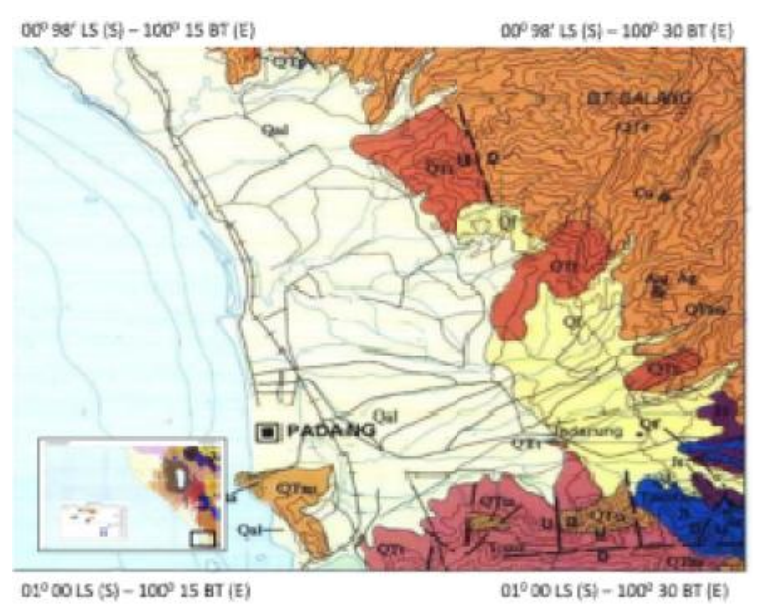

Gambar 1. Peta Geologi Kota Padang (Dinas energi dan sumber daya mineral Provinsi Sumatera Barat, 2012)

Adapun hasil observasi kedalaman sumur yang ada di sekitar wilayah Universitas Negeri Padang Kampus Air Tawar dapat dilihat pada Tabel 1 .

Tabel 1. Kedalaman Sumur yang Terdapat di Sekitar UNP Kampus Air Tawar

\begin{tabular}{|l|l|l|}
\hline No & Lokasi Sumur & $\begin{array}{l}\text { Kedalam } \\
\text { an }\end{array}$ \\
\hline 1. & $\begin{array}{l}\text { Jl. Hamka no. 20 A, } \\
\text { dekat Balai Bahasa }\end{array}$ & 8 meter \\
\hline 2. & $\begin{array}{l}\text { J1. Belibis Blok B } \\
\text { no.14 dekat FIK }\end{array}$ & 6 meter \\
\hline 3. & $\begin{array}{l}\text { Gedung LPMP Dekat } \\
\text { FT }\end{array}$ & 9 Meter \\
\hline 4. & Belakang FIS dekat FE & 6 meter \\
\hline
\end{tabular}

Batuan dapat diketahui dengan mengetahui nilai tahanan jenisnya terlebih dahulu. Salah satu metoda yang digunakan untuk mengetahui nilai tahanan jenis adalah metoda geolistrik tahanan jenis. Prinsip kerja dari metode geolistrik tahanan jenis adalah menginjeksikan arus listrik (I) ke dalam bumi melalui dua elektroda arus sehingga menimbulkan beda potensial. Beda potensial ( $\mathbf{V}$ ) yang terjadi diukur melalui dua elektroda potensial.

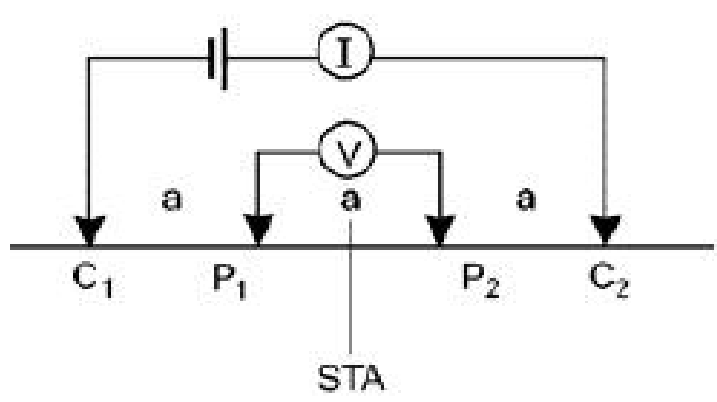

Gambar 2. Konfigurasi Wenner

Gambar 2 merupakan rangkaian elektroda pada konfigurasi Wenner, dimana C1 dan C2 adalah elektroda-elektroda arus, P1 dan P2 adalah elektroda-elektroda potensial, a adalah spasi elektroda.

Penelitian ini peneliti menggunakan metoda geolistrik tahanan jenis konfigurasi Wenner. Keunggulan Metode Geolistrik konfigurasi Wenner diantaranya adalah resolusi vertikalnya bagus, sensitif terhadap perubahan lateral pada daerah yang inhomogenitasnya tinggi dan sering digunakan untuk interpretasi. Adapun rumusan tahanan jenis semu material bawah permukaan bumi untuk konfigurasi Wenner adalah: (Telford, 2004: 655)

$$
\rho_{a}=2 \pi a \frac{\Delta V}{I}
$$

Salah satu program yang biasa digunakan dalam pengolahan data yaitu program Res2Dinv. Program Res2Dinv merupakan salah satu program yang dapat mengolah harga tahanan jenis semu menjadi harga tahanan jenis yang sebenarnya melalui beberapa inversi salah satunya dengan menggunakan inversi Least Square (inversi kuadrat terkecil). Metode kuadrat terkecil (least square) merupakan salah satu metode yang sering digunakan untuk mendapatkan nilai-nilai parameter dalam pemodelan regresi. Adapun persamaan Least Square yaitu:

$$
\begin{aligned}
\left(J^{T} J+\mu F\right) d & =J^{T} g-\mu F r \\
\text { dengan } F & =f_{x} f_{x}^{T}+f_{z} f_{z}^{T}
\end{aligned}
$$


keterangan :

$\mathrm{fx}=$ filter horizontal

$\mathrm{fz}=$ filter vertikal

$\mathrm{J}=$ matrik Jacobian

$\mathrm{J}^{\mathrm{T}}=$ transpors matriks Jacobian

$\mathrm{g}=$ discrepancy vector (vektor ketidakcocokan) hasil pengukuran dengan model

$\mathrm{d}=$ vektor gangguan model dari hasil pengukuran

$\mathrm{r} \quad=$ vektor yang mengandung logaritma dan nilai tahanan jenis model

$\mu=$ faktor damping yang berfungsi untuk mempercepat proses konvergensi

Tujuan penelitian ini adalah untuk mengetahui nilai tahanan jenis batuan dan jenis batuannya. Hasil penelitian ini untuk mengetahui jenis batuan sehingga bisa menjadi informasi bagi pihak pembangunan dalam merancang kontruksi bangunan.

\section{METODE PENELITIAN}

Jenis penelitian ini merupakan penelitian deskriptif yang mendiskripsikan jenis batuan yang terdapat di UNP Kampus Air Tawar berdasarkan nilai tahanan jenisnya menggunakan metoda geolistrik tahanan jenis konfigurasi Wenner.

Tabel 2. Lintasan Pengukuran

\begin{tabular}{|c|c|c|}
\hline Lintasan & Koordinat & Sounding \\
\hline $\begin{array}{l}1(\mathrm{FE}- \\
\text { FIS })\end{array}$ & $\begin{array}{l}00^{0} 53^{\prime} 41,6^{\prime} \text { 'LS dan } \\
100^{0} 20^{\prime} 59,2 \text { 'BT - } \\
00^{0} 53^{\prime} 46,5 \text { 'LS dan } \\
100^{0} 21^{\prime} 00,4 \text { 'BT }\end{array}$ & $\begin{array}{l}00^{0} 53^{\prime} 44,0^{\prime \prime} \mathrm{LS} \\
\text { dan } \\
100^{0} 20^{\prime} 79,8^{\prime \prime} \mathrm{BT}\end{array}$ \\
\hline $\begin{array}{l}2 \\
\text { (Gerbang } \\
\text { UNP - } \\
\text { FT) }\end{array}$ & $\begin{array}{l}00^{0} 53 \text { '52,7'LS dan } \\
100^{0} 21^{\prime} 02,6 \text { 'BT - } \\
00^{0} 53 \text { ' } 53,5 \text { 'LS dan } \\
100^{0} 21^{\prime} 03,1 \text { ' }\end{array}$ & $\begin{array}{l}00^{0} 53^{\prime} 53,1^{\prime}{ }^{\prime} L S \\
\text { dan } \\
100^{0} 21^{\prime} 02,8{ }^{\prime \prime} B T\end{array}$ \\
\hline $\begin{array}{l}3(\mathrm{FIK}- \\
\text { Lab. } \\
\text { Biologi) }\end{array}$ & $\begin{array}{l}00^{0} 53 \text { '55,2'LS dan } \\
100^{0} 20^{\prime} 50,6 \text { 'BT - } \\
00^{0} 53 \text { '42,7'LS dan } \\
100^{0} 20^{\prime} 50,5 \text { 'BT }\end{array}$ & $\begin{array}{l}00^{0} 53^{\prime} 48,9^{\prime}{ }^{\prime} \mathrm{LS} \\
\text { dan } \\
100^{0} 20^{\prime} 50,6^{\prime \prime} \mathrm{BT}\end{array}$ \\
\hline $\begin{array}{l}4 \text { (Balai } \\
\text { Bahasa - } \\
\text { Mesjid } \\
\text { Al } \\
\text { Azhar) }\end{array}$ & $\begin{array}{l}00^{0} 53 ' 58,0^{\prime \prime} \mathrm{LS} \\
\text { dan } 100^{0} 21 \text { '01,6" } \\
\text { BT- } 00^{0} 53,53,5^{\prime}, \\
\text { LS dan } \\
100^{0} 21^{\prime} 03,1^{\prime \prime} \text { BT }\end{array}$ & $\begin{array}{l}00^{0} 53 \text { '55,7' LS } \\
\text { dan } \\
100^{0} 211^{\prime} 02,3 ” \\
\text { BT }\end{array}$ \\
\hline
\end{tabular}

Berdasarkan Tabel 2 dapat dilihat bahwa banyak lintasan pengukuran ada 4 lintasan pengukuran. Dengan koordinat dan titik sounding yang berada pada empat lokasi.

Panjang lintasan pengukuran pada penelitian ini 155 meter dengan jarak antar lektroda adalah 5 meter. Penelitian ini menggunakan ARES (Automatic Resistivity Meter). Adapun teknik pengukuran di lapangan menggunankan ARES adalah sebagai berikut:

1. Membentangkan kabel pada lintasan pengukuran dengan spasi antar elektrodanya sama, pada penelitian ini menggunakan spasi sepanjang $5 \mathrm{~m}$.

2. Menancapkan elektroda pancang pada spasi yang sama dan mengikatkan elektroda arus pada elektroda pancang tersebut.

3. Mengkoneksikan kabel dan accu ke ARES.

4. Men-turn on alat ARES

5. Memasukkan data-data pengukuran ke Ares berupa nama file, lokasi pengambilan data, tanggal penellitian, spasi elektroda, panjang lintasan, beda potensial, kesalahan maksimal dan sebagainya.

6. Setelah itu ARES akan menginformasikan setiap elektroda terkoneksi atau tidak, jika elektroda belum terkoneksi ARES maka dilakukan penambahan larutan garam pada elektroda tersebut. Setelah semua elektroda terkoneksi, lakukan pengukuran pada pilihan menu dan masukkan dipilih adalah konfigurasi Wenner.

7. Menekan press button agar ARES melakukan pengukuran dan menunggu pengukuran sampai selesai dengan pengkodean bunyi alarm dari ARES .

8. ARES melakukan pengukuran secara otomatis, data yang diperoleh akan disimpan pada program ARES. 
9. Mendownload data yang tersimpan di ARES dengan komputer Windows $X P 2$.

10. Menginterpretasikan model gambaran bawah permukaan bumi berdasarkan nilai tahanan jenisnya untuk mengetahui material yang terdapat di bawah permukaan bumi.

Data yang diamati dan diperoleh di lapangan adalah beda potensial ( $V)$, kuat arus (I), dan spasi antar elektroda $(a)$. Data tersebut tersimpan di ARES, tahanan jenis semu diperoleh dari pengukuran otomatis yang dilakukan ARES. Komputer Windows XP2 dibutuhkan untuk mendownload data dari ARES. Data akan diolah dengan program Res2Dinv. Hasil pengolahan data dengan software Res2Dinv dengan inversi Least Squares menggunakan persamaan (2) maka diperoleh profil penampang model 2D bawah permukaan sepanjang lintasan pengukuran yang menggambarkan distribusi tahanan jenis melalui pencitraan warna. Masing-masing warna menunjukkan kode nilai tahanan jenis dari material tertentu. Penampang model 2D tersebut memperlihatkan iterasi hasil inversi dan persen kesalahannya. Tahanan jenis sebenarnya bisa diketahui dengan membandingkan dengan nilai tahanan jenis pada profil penampang model $2 \mathrm{D}$ dengan tabel nilai tahanan jenis batuan, karena rentang nilai tahanan jenis batuan sangat luas, maka di bandingkan lagi dengan jenis batuan yang berada di daerah tersebut yang sesuai dengan informasi dari peta geologi daerah penelitian, yaitu peta geologi Kota Padang, sehingga dapat mengidentifikasi jenis batuan yang terdapat di Universitas Negeri Padang Kampus Air Tawar.

\section{HASIL}

\section{Lintasan 1 (FE - FIS)}

Gambar profil bawah permukaan Lintasan 1 dapat dilihat pada Gambar 3.

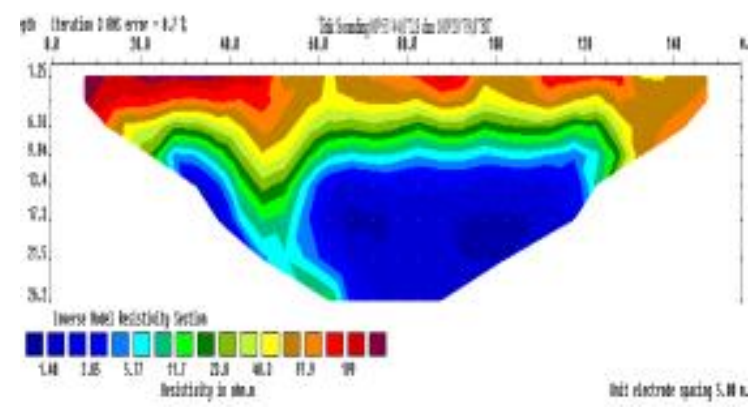

Gambar 3. Profil Bawah Permukaan Lintasan 1 (FE - FIS) dengan titik sounding $00^{0} 53$ ' 44,0 'LS dan $100^{0} 20$ '79,8'BT

Gambar 3 memperlihatkan profil bawah permukaan sepanjang Lintasan 1 dengan titik sounding $00^{0} 53$ '44,0"LS dan $100^{0} 20^{\prime} 79,8^{\prime \prime}$ 'BT. Distribusi nilai tahanan jenis yang terdeteksi pada posisi dan kedalaman tertentu dengan abs. error 8.7 $\%$ pada iterasi ke-3, dari gambar terlihat di atas bahwa Alluvium dan Sands terdapat pada kedalaman $1.25-4.30 \mathrm{~m}$ dengan nilai tahanan jenis 97.9 - $300.1 \quad \mathrm{~m}$ yang ditunjukan dengan warna merah, selanjutnya pada kedalaman $4.30-5.43 \mathrm{~m}$ diperkirakan Sandstones yang mempunyai nilai tahanan jenis 48.3 - 97.9 m yang ditunjukan dengan warna kuning, dan nilai tahanan jenis 8.735 - 48.3 m diperkirakan sebagai Groundwater terdapat pada kedalaman 5.43 - $20 \mathrm{~m}$ yang ditunjukan dengan warna hijau, selanjutnya pada kedalaman > 20 diperkirakan terdapat Saline Water dengan nilai tahanan jenis $0.675-8.735 \mathrm{~m}$ yang ditunjukan dengan warna biru.

Berdasarkan interpretasi data Groundwater diperkirakan pada lintasan 1 ditemukan pada kedalaman $5.43 \mathrm{~m}$, berdasarkan hasil observasi yang dilakukan peneliti didapat bahwa kedalaman sumur bor yang dekat dengan lintasan ini adalah 6 $\mathrm{m}$, yaitu sumur yang terdapat di Belakang FIS dekat FE, hal ini membuktikan bahwa memang ditemukan Groundwater pada kedalaman $5.5 \mathrm{~m}$ karena letak sumur bor kemungkinan memang berada di tengah Groundwater ditemukan untuk mendapatkan air yang bersih. 


\section{Lintasan 2 (Gerbang UNP - FT)}

Gambar profil bawah permukaan Lintasan 2 (Gerbang UNP - FT) dapat dilihat pada Gambar 4.

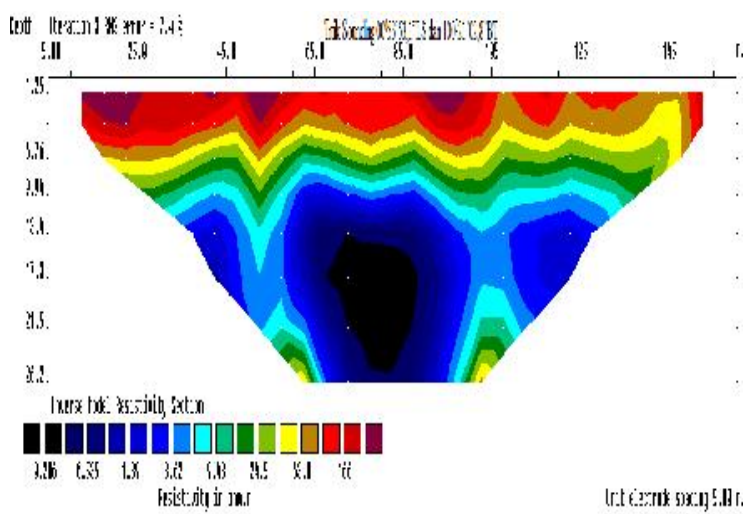

Gambar 4. Profil Bawah Permukaan Lintasan 2 (Gerbang UNP - FT) dengan titik sounding $00^{0} 53$ '53, '”LS dan $100^{0} 21$ '02,8'BT

Gambar 4 memperlihatkan profil bawah permukaan sepanjang Lintasan 2 dengan titik sounding $00^{0} 53^{\prime} 53,1$ ''LS dan $100^{0} 21^{\prime} 02,8$ 'BT. Distribusi nilai tahanan jenis yang terdeteksi pada posisi dan kedalaman tertentu dengan abs. error 7.4 $\%$ pada iterasi ke-3, dari gambar terlihat di atas bahwa Alluvium dan Sands terdapat pada kedalaman $1.25-4.05 \mathrm{~m}$ dengan nilai tahanan jenis 114.0 - $208 \quad \mathrm{~m}$ yang ditunjukan dengan warna merah, selanjutnya pada kedalaman 4.05 - $6.76 \mathrm{~m}$ diperkirakan Sandstones yang mempunyai nilai tahanan jenis $44.15-114.9$ m yang ditunjukan dengan warna kuning, dan nilai tahanan jenis 9.43-44.15 m diperkirakan sebagai Clay terdapat pada kedalaman 6.76 - $8.35 \mathrm{~m}$ yang ditunjukan dengan warna hijau, selanjutnya pada kedalaman $>8.35$ diperkirakan terdapat Groundwater dengan nilai tahanan jenis $0.74-9.45 \mathrm{~m}$ yang ditunjukan dengan warna biru dan diantaranya terdapat Salinewater Salinewater yang mempunyai nilai tahanan jenis $0.04-0.74 \mathrm{~m}$ yang ditunjukan dengan warna hitam.

Berdasarkan interpretasi data Groundwater pada Lintasan 2 dengan titik sounding $\quad 00^{0} 53^{\prime} 53,1^{\prime \prime} \mathrm{LS}$ dan
$100^{0} 21$ '02,8'BT dengan ditemukan kedalaman Groundwater yaitu $8.35 \mathrm{~m}$ dan kedalaman sumur yang didapat dari hasil observasi yaitu $9 \mathrm{~m}$ tepatnya terdapat pada Gedung LPMP dekat FT. Sumur di sini berada pada bagian tengah atau melewati permukaan air tanah untuk mendapatkan air yang bersih.

\section{Lintasan 3 (FIK - Lab. Biologi)}

Gambar profil bawah permukaan Lintasan 3 (FIK - Lab. Biologi) dapat dilihat pada Gambar 5.

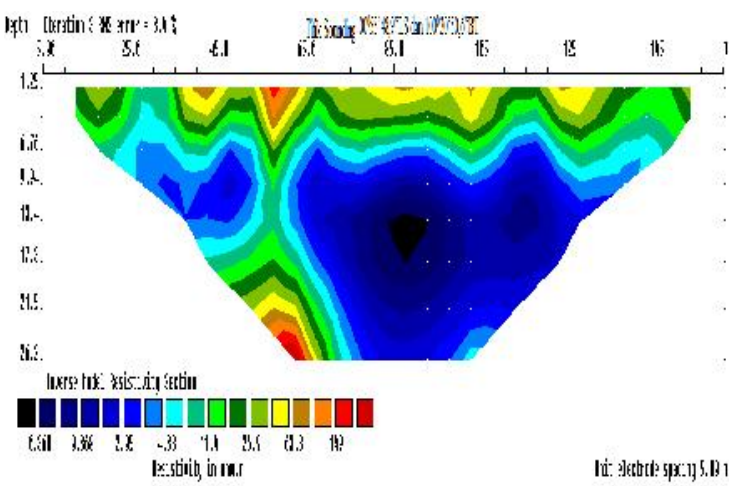

Gambar 5. Profil Bawah Permukaan Lintasan 3 (FIK - Lab. Biologi) dengan titik sounding 00 53 ' 48,9 '"LS dan $100^{0} 20^{\prime} 50,6^{\prime \prime} \mathrm{BT}$

Gambar 5 memperlihatkan profil bawah permukaan sepanjang Lintasan 3 dengan titik sounding 00 03 ' 48 ,9'LS dan $100^{0} 20^{\prime} 50,6$ "BT. Distribusi nilai tahanan jenis yang terdeteksi pada posisi dan kedalaman tertentu dengan abs. error 8.4 $\%$ pada iterasi ke-3, dari gambar terlihat di atas bahwa Alluvium dan Sands terdapat pada kedalaman $1.25-1.50 \mathrm{~m}$ dengan nilai tahanan jenis 106 - $234.7 \quad m$ yang ditunjukan dengan warna merah, selanjutnya pada kedalaman $1.50-2.65 \mathrm{~m}$ diperkirakan Sandstones yang mempunyai nilai tahanan jenis 45.1 - $106.5 \mathrm{~m}$ yang ditunjukan dengan warna kuning, dan nilai tahanan jenis 8.115-45.1 m diperkirakan sebagai Clay terdapat pada kedalaman 2.65 - $5.01 \mathrm{~m}$ yang ditunjukan dengan warna hijau, selanjutnya pada kedalaman > 5.01 diperkirakan terdapat Groundwater dengan 
nilai tahanan jenis $0.368-8.115 \mathrm{~m}$ yang ditunjukan dengan warna biru dan diantaranya terdapat Salinewater Salinewater yang mempunyai nilai tahanan jenis $0.118-0.368 \mathrm{~m}$ yang ditunjukan dengan warna hitam.

Berdasarkan interpretasi data Groundwater pada lintasan 3 diperkirakan kedalaman Groundwater ditemukan > 5.01 $\mathrm{m}$, dan hasil observasi sumur bor yang ditemukan di Jl. Belibis Blok B no 14 ATB dekat FIK di temukan pada kedalaman $6 \mathrm{~m}$. Sumur di sini berada pada bagian tengah atau melewati permukaan air tanah untuk mendapatkan air yang bersih. Hasil observasi sesuai dengan interpretasi data ditemukannya Groundwater.

\section{Lintasan 4 (Balai Bahasa - Mesjid Al Azhar)}

Gambar profil bawah permukaan Lintasan 4 dapat dilihat pada Gambar 6.

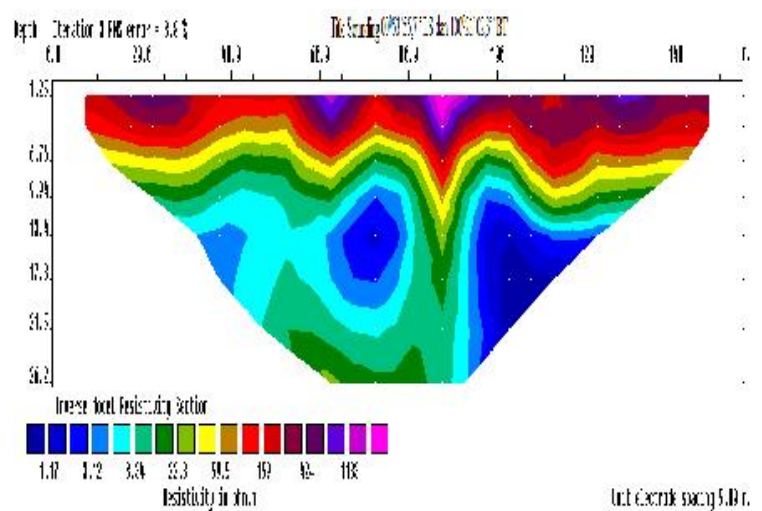

Gambar 6. Profil Bawah Permukaan Lintasan 4 dengan titik sounding $00^{0} 53{ }^{\prime} 55,7$ " LS dan $100^{0} 21$ '02,3" BT

Gambar 6 memperlihatkan profil bawah permukaan sepanjang Lintasan 4 dengan titik sounding $00^{\circ} 53$ ' 55,7 " LS dan $100^{0} 21$ '02,3" BT Distribusi nilai tahanan jenis yang terdeteksi pada posisi dan kedalaman tertentu dengan abs. error 8.8 $\%$ pada iterasi ke-3, dari gambar terlihat di atas bahwa Alluvium dan Sands terdapat pada kedalaman $1.25-5.38 \mathrm{~m}$ dengan nilai tahanan jenis $109.3-1842 \quad \mathrm{~m}$ yang ditunjukan dengan warna merah, selanjutnya pada kedalaman $5.38-6.76 \mathrm{~m}$ diperkirakan Sandstones yang mempunyai nilai tahanan jenis 40.9 - $109.3 \mathrm{~m}$ yang ditunjukan dengan warna kuning, dan nilai tahanan jenis 8.34 - 40.9 m diperkirakan sebagai Clay terdapat pada kedalaman 6.76 - $7.6 \mathrm{~m}$ yang ditunjukan dengan warna hijau, selanjutnya pada kedalaman $>7.6 \mathrm{~m}$ diperkirakan terdapat Groundwater dengan nilai tahanan jenis $0.195-8.35 \mathrm{~m}$ yang ditunjukan dengan warna biru.

Berdasarkan interpretasi lintasan 4 Groundwater diperkirakan ditemukan pada kedalaman $7.6 \mathrm{~m}$, sedang hasil observasi kedalaman sumur yang di temukan di $\mathrm{Jl}$. Hamka no.3 ATB dekat Balai Bahasa yaitu $8 \mathrm{~m}$, sumur di sini berada pada bagian tengah atau melewati permukaan air tanah untuk mendapatkan air yang bersih.

\section{PEMBAHASAN}

Berdasarkan interpretasi data Groundwater diperkirakan pada Lintasan 1 dengan titik sounding $00^{\circ} 53^{\prime} 44,0^{\prime \prime}$ 'LS dan $100^{0} 20^{\prime} 79,8$ "BT ditemukan pada kedalaman $5.43 \mathrm{~m}$. Berdasarkan hasil observasi yang dilakukan peneliti didapat bahwa kedalaman sumur bor yang dekat dengan lintasan ini adalah $6 \mathrm{~m}$, yaitu sumur yang terdapat di Belakang FIS dekat FE. Hal ini membuktikan bahwa memang ditemukan Groundwater pada kedalaman $5.43 \mathrm{~m}$, sedangkan letak sumur bor kemungkinan memang berada di tengah Groundwater ditemukan untuk mendapatkan air yang bersih. Selanjutnya pada Lintasan 2 dengan titik sounding $00^{0} 53$ '53,1'LS dan $100^{0} 21^{\prime} 02,8$ 'BT di temukan kedalaman Groundwater yaitu $8.35 \mathrm{~m}$ dan kedalaman sumur yang didapat dari hasil observasi yaitu $9 \mathrm{~m}$ tepatnya terdapat pada Gedung LPMP dekat FT. Kemudian pada sepanjang Lintasan 3 dengan titik sounding $00^{0} 53^{\prime} 48,9^{\prime}$ 'LS dan $100^{0} 20^{\prime} 50,6$ "BT diperkirakan kedalaman Groundwater ditemukan $5.01 \mathrm{~m}$, dan hasil observasi sumur bor yang ditemukan di Jl. Belibis Blok B no 14 ATB dekat FIK di temukan pada kedalaman $6 \mathrm{~m}$. Terakhir 
pada lintasan 4 dengan titik sounding $00^{0} 53$ '55,7" LS dan $100^{\circ} 21^{\prime} 02,3$ " BT Groundwater diperkirakan ditemukan pada kedalaman $7.6 \mathrm{~m}$, sedang hasil observasi kedalaman sumur yang di lakukan di Jl. Hamka no.3 ATB dekat Balai Bahasa yaitu $8 \mathrm{~m}$, sumur di sini berada pada bagian tengah atau melewati permukaan air tanah untuk mendapatkan air yang bersih.

Groundwater mengelilingi beberapa batuan, diantara batuan itu diperkirakan Alluvium dan Sands yang terdapat pada lapisan atas, lapisan selanjutnya ada Sandstones, kemudian ada lapisan Clay sebelum Groundwater yang ada pada lapisan paling bawah. Menurut kondisi geologi kota padang bahwa lingkungan fisik yang menyusun kota padang adalah Alluvium (Qal) batuan aluvium (Qa) yang merupakan satuan batuan termuda yang pembentukannya masih berlangsung terus menerus hingga saat ini, dan berasal dari rombakan batuan yang lebih tua. Satuan batuan ini terdiri atas kerikil, pasir, lanau, dan lempung yang merupakan endapan sungai dan kalau dilihat dari hasil penelitian yang di dapat bahwa wilayah UNP sesuai dengan peta geologi kota padang.

Berdasarkan hasil penelitian yang dilakukan oleh Media (2012) menggunakan metoda geolistrik tahanan jenis konfigurasi Dipole-dipole, jenis batuan yang terdapat di Universitas Negeri Padang Kampus Air Tawar, terdiri dari Alluvium, Sandstones, Sands dan Clays, serta Andesite sebagai jenis batuan dasar. Menurut hasil interpretasi dari Nelvira (2012) menggunakan metoda geolistrik tahanan jenis konfigurasi Shlumberger, jenis batuan yang terdapat di Universitas Negeri Padang Kampus Air Tawar, terdiri dari Alluvium, Sandstones, Sands dan Clays dan jenis batuan dasar juga yang di perkirakan adalah Andesite.

\section{KESIMPULAN}

Berdasarkan analisis data tahanan jenis 2D konfigurasi Wenner yang dilakukan di Kampus Air Tawar Universitas Negeri Padang Kecamatan Padang Utara Kota Padang dapat disimpulkan:

1. Rentang nilai tahanan jenis pada lintasan 1 (FE-FIS) dari 0.675 - 300.1 $\mathrm{m}$, lintasan 2 (Gerbang Utama-FT) 0.0145 - $208 \mathrm{~m}$, lintasan 3 (FIK-Lab. Biologi) antara 0.118 - $243.7 \mathrm{~m}$, lintasan 4 (Balai Bahasa-Mesjid Al Azhar) dari $0.195 \mathrm{~m}-1842 \mathrm{~m}$.

2. Jenis batuan pada keempat lintasan diperkirakan Groundwater, Clay, Sandstones, Alluvium dan Sands.

\section{UCAPAN TERIMA KASIH}

Penelitian ini didanai oleh DP2M DIKTI melalui PKM-P. Terima kasih disampaikan kepada Bapak Akmam dan Ibu Fatni MufitSebagai Pembimbing. Media Febrina, Nelvira Rizalmi, Edi kurnia, Nofri Hardisal, Yoggy Refiyon dan Teman-teman geolistrik 2009 yang telah membantu selama penelitian. Bapak Tunsri Febrison dan Bapak Ahmad Samsuardi atas bantuannya secara tekhnis dalam penggunaan alat penelitian.

\section{DAFTAR PUSTAKA}

Akmam. (2006). "Studi Terhadap Air Tanah Padang Simawang Kecamatan Rambatan dengan Metoda Inversi Least-Square Dua Dimensi." Jurnal Sainstek. 2 (III). Hlm. 193-197.

Biro Administrasi Perencanaan dan sistem Informasi Universitas Negeri Padang. 2010. Denah UNP. Padang: UNP.

Danida. 2009. "Laporan KLHS Kota Padang". Laporan penelitian. Bina Pembangunan Daerah.

LIPI - UNESCO/ISDR, 2006. (online) http://www.jtic.org dikses tanggal 19 februari 2012. 
Munir, Moch. 1996. Geologi dan Mineral Tanah. Jakarta: PT. Dunia Pustaka Jaya.

Nurdin, Ade Akhyar. 2009. Dasar-Dasar Mikropaleontotogi. Purbalingga: Fakultas Sains dan Teknik Universitas Jenderal Soedirman.
Telford, W.M. 2004. Applied Geophysics Second Edition, Cambridge: University.

Verhoef, P.N.W.1994.Geologi Untuk Tehnik Sipil. Terjemahan. E.Diraatmaja. cetakan ketiga. Jakarta : Erlangga. 